Check for updates

Cite this: J. Mater. Chem. C, 2019, 7, 8593

\title{
Beyond efficiency: phenothiazine, a new commercially viable substituent for hole transport materials in perovskite solar cells $\dagger$
}

\author{
Michal R. Maciejczyk, (D) ${ }^{a}$ Ruihao Chen, (D) ${ }^{b}$ Alasdair Brown, (D) ${ }^{a}$ \\ Nanfeng Zheng (D) *b and Neil Robertson (D)*a
}

\begin{abstract}
Two triphenylbenzene (TPB) derivatives, 1,3,5-tris( $2^{\prime}-((N, N$-di(4-methoxyphenyl)amino)phenyl))benzene (TPB(2-MeOTAD)) and 1,3,5-tris(2'-(N-phenothiazylo)phenyl)benzene (TPB(2-TPTZ)), have been synthesized via two cost-efficient two step processes, and fully characterized by ${ }^{1} \mathrm{H} /{ }^{13} \mathrm{C}$ NMR spectroscopy and mass spectrometry. For the first time in perovskite solar cells, phenothiazine has been introduced, as a low cost substituent to replace commonly used dimethoxydiphenylamine, which constitutes almost $90 \%$ of the final cost of hole transporting materials (HTMs). The use of a more flexible central core than state of the art spirobifluorene (SBF) lowers the highest occupied molecular orbital (HOMO) energy level, increases solubility and decreases the glass transition temperature. The derivatives were employed as hole-transport materials for the fabrication of mesoporous $\mathrm{ZnO}-\mathrm{Mg}-\mathrm{EA}\left(\mathrm{NH}_{3}{ }^{+}\right) / \mathrm{CH}_{3} \mathrm{NH}_{3} \mathrm{Pbl} / 3 / \mathrm{HTM} / \mathrm{Au}$ solar cells. The best cells obtained have an optimized PCE of $12.14 \%$ and $4.32 \%$ for cells based on $4,4^{\prime}$-dimethoxydiphenylamine and phenothiazine substituents, respectively. Due to the extremely low cost of TPB(2-TPTZ) which is equal to $3.43 \$ \mathrm{~g}^{-1}$, in solar cells it delivers the lowest cost per peak Watt of $0.014 \$$ per $W_{p}$, which is 15 times lower than spiro-MeOTAD. This shows that the approach is commercially viable with potential to deliver HTMs with a cost contribution to the final module of as little as $1 \%$.
\end{abstract}

Received 16th November 2018 Accepted 24th June 2019

DOI: $10.1039 / \mathrm{c} 8 \mathrm{tc} 05773 \mathrm{~g}$

rsc.li/materials-c

\section{Introduction}

Organic-inorganic lead halide perovskite solar cells (PSCs), due to superior attributes such as high efficiency, low cost and simple manufacturing with possible roll-to-roll processing, have attracted significant attention both in academia and in industry. ${ }^{1-3}$ The typical structure of PSCs includes a light-absorbing layer sandwiched between an electron transport material (ETM) and a hole transport material (HTM). The role of the HTM is to facilitate hole extraction and retard charge recombination at the interface between the HTM and the perovskite layer. To fulfil these requirements ideal materials have good hole transport capacity and conductivity, high mobility, ${ }^{4}$ the highest occupied molecular orbital (HOMO) energy level should be well aligned with the valence band of the

\footnotetext{
${ }^{a}$ School of Chemistry and EaStCHEM, University of Edinburgh, King's Buildings, David Brewster Road, Edinburgh, Scotland EH93FJ, UK. E-mail: Neil.Robertson@ed.ac.uk,nfzheng@xтu.edu.cn

${ }^{b}$ State Key Laboratory for Physical Chemistry of Solid Surfaces, Collaborative Innovation Center of Chemistry for Energy Materials, and Department of Chemistry, College of Chemistry and Chemical Engineering, Xiamen University, 422 Siming South Road, Xiamen 361005, China

$\dagger$ Electronic supplementary information (ESI) available: DSC and TGA curves, electrochemical characteristics, XRD powder patterns, device performance, solubility studies, ${ }^{1} \mathrm{H}$ and ${ }^{13} \mathrm{C}$ NMR spectra. See DOI: 10.1039/c8tc05773g
}

perovskite material, ${ }^{5}$ good solubility to facilitate processability and low cost to justify their use. ${ }^{6}$

The most commonly used state-of-the-art HTM 2,2',7,7'tetrakis-( $N, N$-di-p-methoxyphenylamine)-9, $9^{\prime}$-spirobifluorene (spiroOMeTAD) can deliver efficiency as high as $22.0 \%,{ }^{7}$ which is close to the record certified efficiency of $22.7 \%,{ }^{8}$ but its tedious multistep synthesis and complicated doping process to achieve sufficient conductivity, leading to high price and low stability, stimulates further research to find more cost efficient and dopant-free candidates. To fulfil these requirements numerous novel hole transport materials have been introduced. For instance, the most recent reports with the reference device efficiency based on spiro-OMeTAD given in parentheses include structures like: spiro[fluorene-9, $9^{\prime}$-phenanthren-10-one] - 16.06\% (16.08\%); ${ }^{9}$ spiro[dibenzo[c,h]xanthene-7, $9^{\prime}$-fluorene] - 15.9\% (10.8\%) for undoped HTMs; ${ }^{10}$ 2,5,9,12-tetra(tert-butyl)diacenaphtho[1,2- $b$ : $1^{\prime}, 2^{\prime}$-d] thiophene with $15.59 \%$ (16.5\%-doped) and $18.17 \%$ (18.30\%doped) efficiencies for undoped HTMs with n-i-p planar and mesoscopic architectures, respectively; ${ }^{11}$ carbazole modified fluorene branched structures - 18.3\% (18.9\%); ${ }^{12}$ diphenylamine substituted carbazole - 18.92\% (18.79\%); ${ }^{13}$ anthanthrone based HTMs with $17.5 \%$ (16.8\%-doped) efficiency for undoped HTMs; ${ }^{14}$ pyrene based HTMs - 18.23\% (16.00\%); ${ }^{15}$ phenothiazine based HTMs $19.17 \%$ (19.66\%); ${ }^{16}$ fluoranthene based HTMs with $18.03 \%$ (9.33\%) 
efficiency for undoped HTMs $;{ }^{17}$ fluorene terminated spiro HTMs with $22.3 \%$ (21.3\%) efficiency. ${ }^{18}$ This shows that by appropriate molecular engineering, comparable or even greater efficiency than for spiro-MeOTAD can be achieved, especially when no dopants are used.

Our recent findings ${ }^{6}$ on PSCs with architecture $\mathrm{TiO}_{2} /$ mesoAl $_{2} \mathrm{O}_{3} /$ $\mathrm{MAPbI}_{3-x} \mathrm{Cl}_{x} / \mathrm{HTM}$ showed that the interchange of the core unit from spiroMeOTAD, namely spirobifluorene (SBF) with the product of one-pot reaction of fluorenone and phenol in the presence of methanesulfonic acid without any solvent spiro[fluorene-9,9'xanthene] (SFX) to afford SFX-MeOTAD ${ }^{19}$ leads to a comparable power conversion efficiency (PCE) but more than 5 times lower cost. This material, also simultaneously reported as X60, ${ }^{20}$ has been independently investigated by other researchers as a HTM for PSCs to obtain an efficiency of $19.8 \%\left(\mathrm{TiO}_{2} / \mathrm{nc}_{-} \mathrm{TiO}_{2} / \mathrm{FAPbI}_{3}-\right.$ $\left.\mathrm{PbI}_{2}-\mathrm{MABr}-\mathrm{PbBr}_{2} / \mathrm{HTM}\right),{ }^{20} 16.8 \%\left(\mathrm{TiO}_{2} / \mathrm{mesoTiO}_{2} / \mathrm{MAPbI}_{3} / \mathrm{HTM}\right)$, $17.7 \%\left(\mathrm{TiO}_{2} / \mathrm{mesoTiO}_{2} / \mathrm{FAPbI}_{3}-\mathrm{MAPbBr}_{3} / \mathrm{HTM}\right){ }^{21}$ and $19.0 \%\left(\mathrm{TiO}_{2} /\right.$ mesoTiO $\left.{ }_{2} / \mathrm{FAPbI}_{3}-\mathrm{MAPbBr}_{3} / \mathrm{HTM}(\mathrm{TFSI})_{2}\right)^{22}$ or to study the charge transfer dynamics and effects of molecular symmetry, ${ }^{23,24}$ leaving SFX-MeOTAD the second most studied low molecular HTM, as a successor to spiro-MeOTAD. However, the need to match the HOMO energy level of the HTM with the valence band maxima of a variety of perovskites with larger bandgaps calls for further development of HTMs with tuned HOMO energies. Unfortunately, utilizing substituents other than 4,4'-dimethoxydiphenylamine on the SFX core, like carbazole or phenothiazine with significantly lower HOMO levels, leads to insoluble materials. To solve this problem Chiykowski et al. have studied the influence of the selective placement of 4,4'-dimethoxydiphenylamine onto the SFX core leading to control over the hole mobility, the glass transition temperature and the HOMO level, achieving a power conversion efficiency (PCE) of $20.8 \%{ }^{25}$ The cost of the substituent materials, however, is also an important factor. The commercial price was estimated (based on the cheapest offer and the largest quantity available from common suppliers) to be $6.80 \mathrm{~S} \mathrm{~g}^{-1}$ for $4,4^{\prime}$ dimethoxydiphenylamine, $0.02 \mathrm{~S} \mathrm{~g}^{-1}$ for phenothiazine and $0.19 \mathrm{~S} \mathrm{~g}^{-1}$ for carbazole. It is clear that phenothiazine in particular is a very cost-effective material, as it can be purchased in kilogram quantities, over 300 times less expensive than 4,4'dimethoxydiphenylamine which according to our previous cost estimation $^{6}$ accounts for almost $90 \%$ of the material's cost of Buchwald-Hartwig amination. Additionally, sulfur based heterocycles have been found to strengthen the interaction between the perovskite and the HTM; ${ }^{16,26-28}$ however, the low solubility of phenothiazine and carbazole-substituted molecules has limited their use in hole-transport materials for PSCs. Therefore, developing materials that do not require this pricy substituent at all, or can use cost effective analogues that can also tune HOMO levels, is of high interest. As has been discussed by Osedach et al. ${ }^{29}$ to make materials in organic photovoltaics commercially viable, the synthesis has to be scaled to thousands of kilograms. Moreover, the cost of the material has to be small, normally requiring a small number of synthetic steps, as the cost increases linearly with the number of steps. Thus, high efficiency in solar cells shows the prospects for the technology but does not indicate its commercial viability. The authors of the paper cited above concluded that material costs for organic photovoltaics should be in the range of $1-10 \%$ of the module cost. This puts restrictions on the individual active layer price, which should be less than 0.005 or $0.050 \$$ per $\mathrm{W}_{\mathrm{p}}$. The importance of the cost of the hole transporting material in perovskite solar cells has been well identified by researchers and targeted in a number of publications, but the main emphasis has been mainly on designing new cores that utilize 4,4'-dimethoxydiphenylamine as a substituent which delivers the desirable HOMO energy level.

Therefore, in our work we have introduced, for the first time in perovskite solar cells, phenothiazine as a low cost substituent to replace the almost-exclusively used 4,4'-dimethoxydiphenylamine. We report synthesis, photophysical and device studies of a novel approach to easily accessible ortho substituted triphenylbenzene (TPB) based hole conductors. The materials presented possess high solubility, good thermal stability and a low HOMO level around $-5.3 \mathrm{eV}$. The fabricated devices (non-optimized) have PCEs of $12.14 \%$ and $4.32 \%$ for cells based on $4,4^{\prime}$-dimethoxydiphenylamine and phenothiazine substituents, respectively and further optimization may significantly improve device performances. We have implemented these materials in a recently developed novel device structure which replaces the typically-used electron transporting material, titanium dioxide, with ZnO ETM modified with a thin layer of $\mathrm{MgO}$ and a sub-monolayer of protonated ethanolamine (EA); this architecture has been optimized up to a high efficiency of $21.1 \%$ and no hysteresis was observed when the spiro-MeOTAD HTM was utilized. ${ }^{30}$

\section{Results and discussion}

\section{Synthetic procedures and characterization}

The starting material for this reaction, 1,3,5-tris(2-bromophenyl)benzene, is not commercially available. However, it can be simply synthesised by an aldol condensation reaction of $2^{\prime}$-bromoacetophenone with cost efficient and accessible reagent-silicon tetrachloride. ${ }^{31}$ The next and final step (Fig. 1) leading to novel hole transporting materials used Buchwald-Hartwig coupling affording good $73 \%$ to moderate $50 \%$ reaction yields for TPB(2-MeOTAD) and $\mathbf{T P B}(2-\mathbf{T P T Z})$, respectively. Thus, the complexity of the synthetic procedures required to produce these materials was low throughout. All of the analytical data $\left({ }^{1} \mathrm{H} /{ }^{13} \mathrm{C}\right.$ NMR spectroscopy, mass spectrometry and elemental analysis) can be found in the ESI. $\dagger$

To assess the material cost of the HTM we have used a procedure reported by Osedach $e t$ al. for materials in organic photovoltaics and followed the work by Petrus et al. which introduced it to the field of HTMs for perovskites. ${ }^{29,32,33} \mathrm{We}$ have simplified the cost estimation by omitting the costs of workup and purification since on the small scale chlorinated solvents and column chromatography increase the cost of the final material significantly but these steps would be substituted by the appropriate solvent choice and the recrystallization procedure on the process development stage. The estimated cost of the materials for the central 1,3,5-tris(2-bromophenyl)benzene core is $1.64 \mathrm{~S} \mathrm{~g}^{-1}$; for the final HTMs we found $12.98 \mathrm{~S} \mathrm{~g}^{-1}$ and $3.09 \mathrm{~S} \mathrm{~g}^{-1}$ 


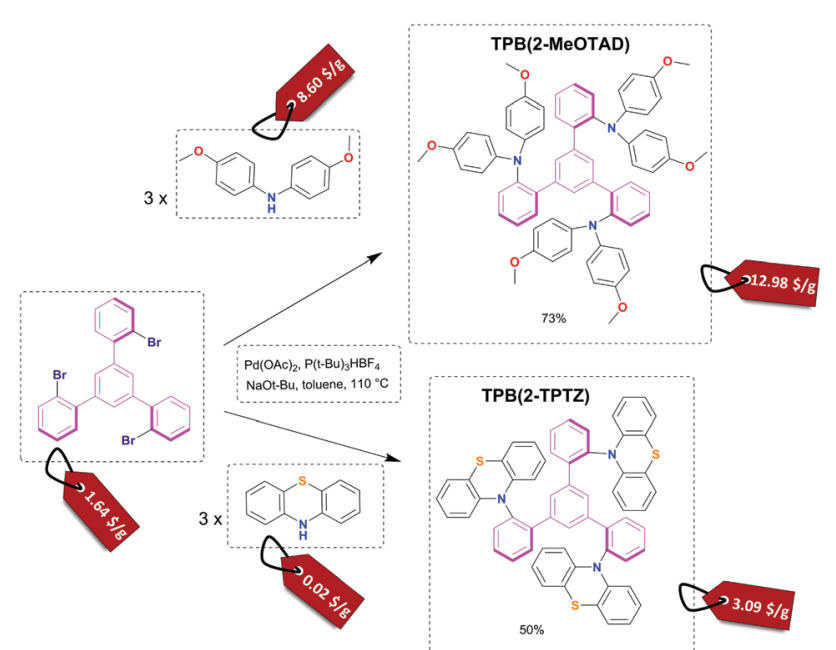

Fig. 1 Reaction scheme for the Buchwald-Hartwig amination of 1,3,5tris(2-bromophenyl)benzene with 4,4'-dimethoxydiphenylamine and phenothiazine with estimated cost on the price tag.

for TPB(2-MeOTAD) and TPB(2-TPTZ), respectively (see the ESI, $\dagger$ from more details). These costs are much lower than the price of state-of-the-art spiro-MeOTAD which can be within the range of 100 to $400 \mathrm{~S} \mathrm{~g}^{-1}$. Such low material costs are due to only two reaction steps and low precursor costs. In particular, the phenothiazine substituent has tremendous potential due to an extremely low cost of only $0.02 \mathrm{~S} \mathrm{~g}^{-1}$ which constitutes only $1 \%$ of the cost in comparison with around $85 \%$ for dimethoxydiphenylamine. At the same time TPB(2-TPTZ) has a good match of its HOMO energy level with the valence band of the perovskite absorber.

The solubility of all three products was assessed in three different solvents: chlorobenzene, chloroform and toluene. Both materials were easily soluble in chloroform, toluene and chlorobenzene (Table S2, ESI $\dagger$ ) with the lowest solubility for TPB(2-MeOTAD) of $50 \mathrm{mg} \mathrm{m}{ }^{-1}$ in chlorobenzene and the highest solubility for TPB(2-TPTZ) of $260 \mathrm{mg} \mathrm{ml}^{-1}$ in chloroform and moderate solubility for both of materials in toluene at the level of $150 \mathrm{mg} \mathrm{ml}{ }^{-1}$. This contrasts with our previously reported $^{6}$ derivatives based on the SFX core with phenothiazine and carbazole substituents which showed very low solubilities less than $10 \mathrm{mg} \mathrm{ml}^{-1}$. Even though the addition of an oxygen atom to change the SBF spiro-structure into the SFX brings improved solubility and processability, this effect is insufficient when more planar substituents are introduced. Thus, it is clear that the triphenylbenzene core improves solubility dramatically, attributed to the free rotation of the bonds between the central benzene and the phenyl groups typical in TPBs. This should allow the molecule to dissolve more easily as it has more freedom to reorient in solution. As such, even when rigid, planar phenothiazine was employed, the solubility of the hole transport material was retained. All of these factors are advantages for the scalability of the reaction and materials accessibility since the solubilizing groups on the amine derivatives are not required as they would be in the case of the spiro core. This is particularly relevant for the phenothiazine substituent, which has been recently used to prepare HTMs with high thermal stability, a large Stokes shift and a hole mobility of $2.08 \times 10^{-3} \mathrm{~cm}^{2} \mathrm{~V}^{-1} \mathrm{~s}^{-1}$ with the energy level very well matched with $\mathrm{CH}_{3} \mathrm{NH}_{3} \mathrm{PbI}_{3}$ but suffering from impractically low solubility. ${ }^{34}$

\section{Electrochemical and optical properties}

Cyclic voltammetry was run between -2.00 and $+2.00 \mathrm{~V}$ to check for reduction processes at the negative potential (Fig. S3, ESI $\dagger$ ). None were visible for either material in the solvent window used. Therefore, the LUMO energy levels could not be estimated from the electrochemical data. The oxidation potentials $\left(E_{\text {ox }}\right)$ of TPB(2-MeOTAD) and TPB(2-TPTZ) were elucidated by cyclic and square-wave voltammetry. Against ferrocene/ferrocenium as the internal standard, the oxidation potentials of TPB(2-MeOTAD) and $\mathbf{T P B}(2-\mathbf{T P T Z})$ were $0.19 \mathrm{~V}$ and $0.24 \mathrm{~V}$ respectively. These values were used to estimate the energy of the highest occupied molecular orbital $\left(E_{\mathrm{HOMO}}\right)$ of each material. Accordingly, TPB(2-MeOTAD) and TPB(2-TPTZ) gave $E_{\text {НОмо values of }-5.29 \mathrm{eV} \text { and }}$ $-5.34 \mathrm{eV}$ respectively. Both values are clearly lower than the benchmark material spiro-MeOTAD $(-5.14 \mathrm{eV})$. Thus, TPB(2-MeOTAD) and TPB(2-TPTZ) have $E_{\mathrm{HOMO}}$ levels which are closer in energy to the valence band of $\mathrm{MAPbI}_{3}(-5.44 \mathrm{eV})$, the most commonly employed perovskite material. This indicates that hole injection from $\mathrm{MAPbI}_{3}$ is favourable. Furthermore, as the open-circuit voltage $\left(V_{\mathrm{OC}}\right)$ is strongly linked to the difference between the quasi-Fermi level of the electron transport material and the HOMO level of the HTM, ${ }^{35}$ the lower $E_{\mathrm{HOMO}}$ could increase the $V_{\mathrm{OC}}$. The cyclic and square wave voltammetry plots against ferrocene for each material are shown in Fig. 2 and the peaks are tabulated in Table 1. The electrochemical reversibility of each oxidation process was assessed by running measurements at different scan rates (Fig. S1, ESI $\dagger$ ). For both TPB(2-MeOTAD) and TPB(2-TPTZ), $E_{\mathrm{pa}}$ and $E_{\mathrm{pc}}$ were found to be independent of the scan rate and $I_{\mathrm{pa}}$ and $I_{\mathrm{pc}}$ showed a linear dependence on the square root of the scan rate (Fig. S2, ESI $\dagger$ ). Thus, the oxidation peaks for both materials were electrochemically reversible.

UV-Visible spectroscopy was conducted on TPB(2-MeOTAD) and $\mathbf{T P B}(2-\mathbf{T P T Z})$ in dichloromethane (Fig. 3). Both absorb in the UV region, with maximum absorption wavelengths of 300 and $323 \mathrm{~nm}$, respectively. The optical band gaps $\left(E_{\text {gap }}\right)$ were estimated from the onset of absorption. From these $E_{\text {gap }}$ values and

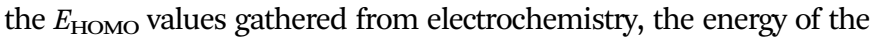
lowest unoccupied molecular orbitals $\left(E_{\mathrm{LUMO}}\right)$ was estimated.
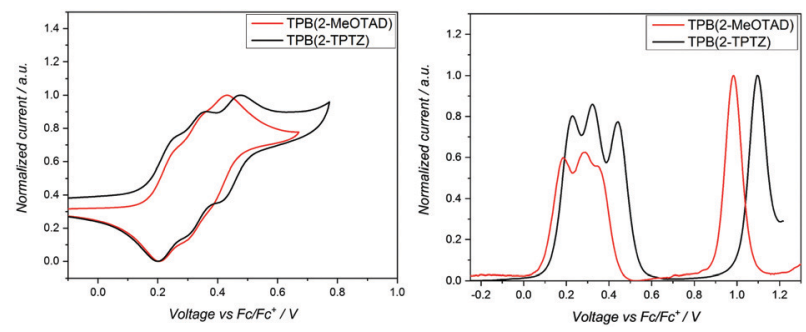

Fig. 2 Cyclic voltammograms (CV) (left) and square wave voltammetry (SWV) of TPB(2-MeOTAD) and TPB(2-TPTZ) in DCM solution with supporting electrolyte $0.3 \mathrm{M}$ tetrabutylammonium hexafluorophosphate referenced to ferrocene. 
Table 1 Electrochemical, photophysical and thermal properties

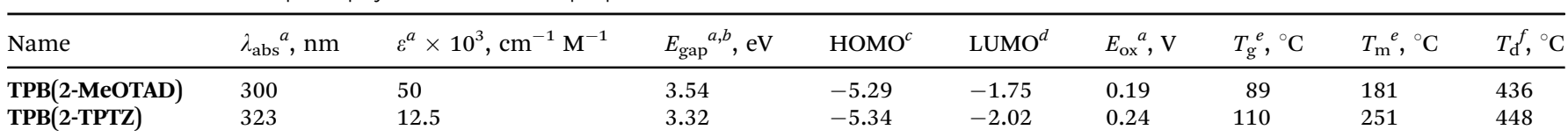

${ }^{a}$ In dichloromethane solution. ${ }^{b}$ Optical gap, from intersection of Abs and Pl. ${ }^{c} E_{\mathrm{HOMO}}=-5.1-\left(E_{\mathrm{ox}}\right) \cdot{ }^{36 d} E_{\mathrm{LUMO}}=E_{\mathrm{HOMO}}+E_{\text {gap. }}{ }^{e} \mathrm{Glass}$ transition temperature $\left(T_{\mathrm{g}}\right)$ and melting point $\left(T_{\mathrm{m}}\right)$ by DSC. ${ }^{f}$ Decomposition temperature $\left(T_{\mathrm{d}}\right)$ by TGA.

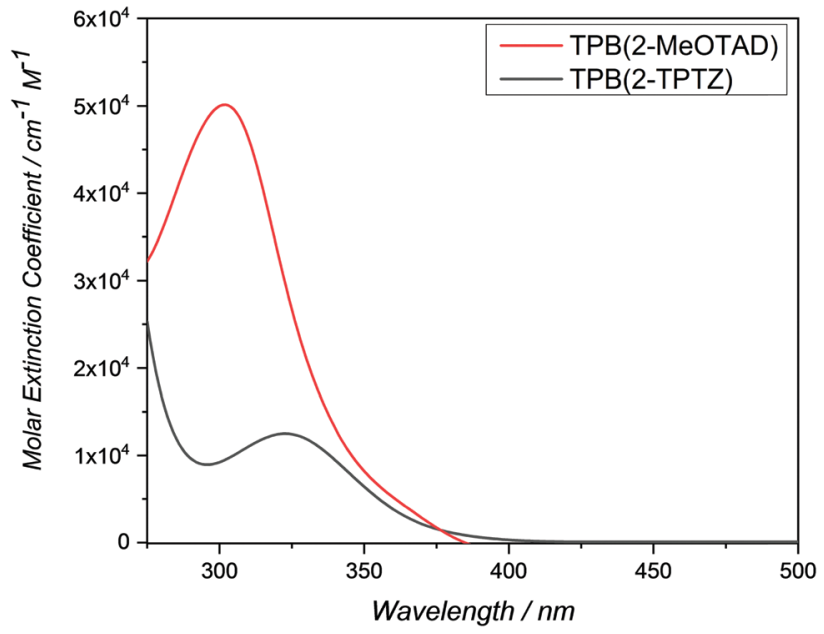

Fig. 3 UV/Visible absorption of TPB(2-MeOTAD) and TPB(2-TPTZ) in diluted DCM.

\section{Thermal analysis}

Differential scanning calorimetry (DSC) was conducted for TPB(2-MeOTAD) and TPB(2-TPTZ) (Fig. S4 and S6, ESI $\dagger$ ). Glass transitions were recorded at 89 and $110{ }^{\circ} \mathrm{C}$ for TPB(2-MeOTAD) and $\mathbf{T P B}(2-\mathbf{T P T Z})$ respectively. The dimethoxydiphenylamine substituent is comprised of two independently-flexible phenyl rings, whereas the entire phenothiazine substituent must arrange as a single unit. It is probable that this greater rigidity and planarity of TPB(2-TPTZ) inhibits organisation into a crystal structure, hence a greater thermal energy was required to destabilise the amorphous state. The glass transitions of both materials are lower than spiro-MeOTAD $\left(122{ }^{\circ} \mathrm{C}\right)$. The melting points were observed for both: $\mathbf{T P B}\left(2\right.$-MeOTAD) melted at $181{ }^{\circ} \mathrm{C}$ and $\mathbf{T P B}(2-\mathbf{T P T Z})$ at $251{ }^{\circ} \mathrm{C}$. This value for $\mathbf{T P B}(2-\mathbf{T P T Z})$ is higher than that of spiro-MeOTAD, confirming that it has high thermal stability.

Thermogravimetric analysis (TGA) of TPB(2-MeOTAD) and TPB(2-TPTZ) revealed that both were thermally stable with respect to decomposition (Fig. S5 and S7, ESI $\dagger$ ). A mass loss of 5\% occurred at $436{ }^{\circ} \mathrm{C}$ for $\mathbf{T P B}(2-\mathrm{MeOTAD})$ and $448{ }^{\circ} \mathrm{C}$ for $\mathbf{T P B}(2-\mathrm{TPTZ})$.

\section{XRD analysis}

The powder X-ray diffraction (PXRD) patterns of TPB(2-MeOTAD) and TPB(2-TPTZ) were obtained (Fig. S8, ESI $\dagger$ ). The PXRD plot for TPB(2-TPTZ) showed more well-defined and intense peaks than that of TPB(2-MeOTAD). This indicates that TPB(2-TPTZ) has more crystalline character. It is possible that greater crystallinity would lead to the decrease in the $\pi-\pi$ stacking distance, leading to increased intermolecular orbital interactions as we previously showed for the related compound based on the SFX core. ${ }^{6}$ Moreover, this would improve the mobility of holes through the material as has been observed for other materials with planar substituents like tetra-carbazole and phenothiazine substituted SFX with mobility as high as $1.57 \times 10^{-3} \mathrm{~cm}^{2} \mathrm{~V}^{-1} \mathrm{~s}^{-1}$ and a hole mobility of $2.08 \times 10^{-3} \mathrm{~cm}^{2} \mathrm{~V}^{-1} \mathrm{~s}^{-1}$, respectively. ${ }^{37,38}$

\section{Photovoltaic performance}

In order to investigate the suitability of TPB(2-MeOTAD) and TPB(2-TPTZ) as HTMs in perovskite solar cells, devices with a structure (Fig. 4) of $\mathrm{FTO} / \mathrm{ETM} / \mathrm{m}-\mathrm{TiO}_{2} / \mathrm{MAPbI}_{3} / \mathrm{HTM}$ were fabricated, in which the HTMs are either the new materials or spiro-OMeTAD as the reference material. $\mathrm{ZnO}-\mathrm{Mg}-\mathrm{EA}\left(\mathrm{NH}_{3}{ }^{+}\right)$ layer acted as an effective ETM. ${ }^{30}$ A detailed procedure is shown in the ESI. $\dagger$

The better matched HOMO levels between the new materials and the perovskite should facilitate efficient hole transfer and extraction with minimal energy loss. Additionally, the high LUMO energy level of TPB(2-MePTAD) $(-1.75 \mathrm{eV})$ and TPB(2-TPTZ) $(-2.02 \mathrm{eV})$ will effectively block electrons to prevent recombination at the anode. The cross-sectional view and topview of the device is shown in Fig. 5; the thickness of the photoactive layer is $\approx 700 \mathrm{~nm}$ and the HTL thickness is $\approx 200 \mathrm{~nm}$. When the perovskite film is coated with our HTM materials a uniform and smooth morphology is observed for TPB(2-MeOTAD), while for the cell with phenothiazine based materials a blurred and rough surface can be seen.

The current density-voltage $(J-V)$ curves for the best devices based on the new HTMs were investigated under standard air mass (AM) 1.5 conditions and the results are shown in Fig. S9 (ESI $\dagger$ ).

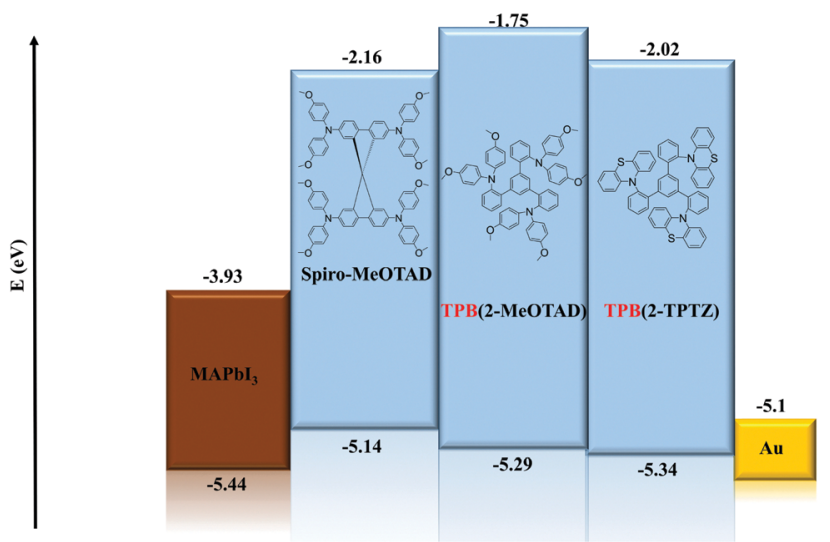

Fig. 4 Energy level diagram and device architecture of perovskite solar cells. 


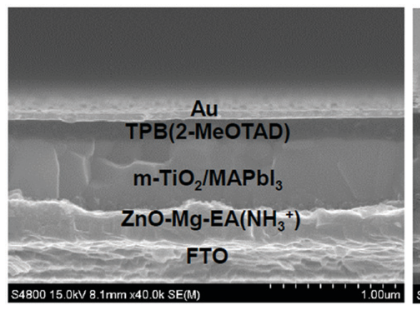

TPB(2-MeOTAD) device

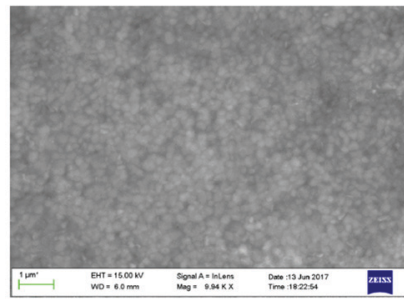

TPB(2-MeOTAD)

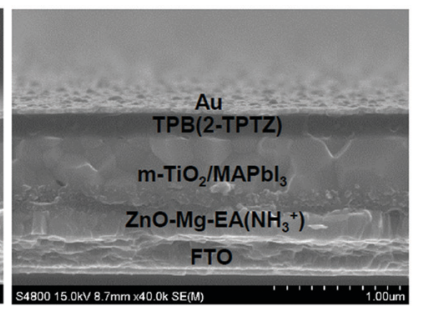

TPB(2-TPTZ) device

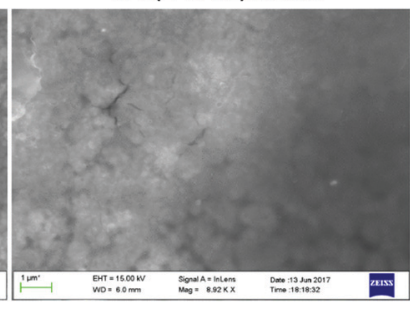

TPB(2-TPTZ)
Fig. 5 Cross-sectional (top) and top-view (bottom) SEM images of PSCs with TPB-2-MeOTAD and TPB(2-TPTZ) as HTMs.

We have performed device optimization by testing different concentrations of hole conductors being deposited. Solutions with $35 \mathrm{mg} \mathrm{ml}{ }^{-1}$ concentration were found to lead to the best film quality according to SEM images and the highest efficiency in PSCs, for more information see the ESI. $\dagger$ The best-performing cell based on TPB(2-MeOTAD) exhibited an efficiency of $12.14 \%$ while the cell based on TPB(2-TPTZ) exhibited $4.32 \%$ (see Table 2 ). The device performance statistics of 18 individual cells at forward (FS) and reverse scans (RS) are shown in Fig. S11 (ESI $\dagger$ ). The reference device based on spiroMeOTAD showed a PCE of $18.04 \%$, as shown in Fig. S13 (ESI $\dagger$ ). The hysteresis behaviour of PSC devices with TPB(2-MeOTAD) and TPB(2-TPTZ) as HTMs is determined through forward and reverse scans. The corresponding incident photon-to-electron conversion efficiency (IPCE) spectra of TPB-based devices as well as the related integrated photocurrents of the champion solar cells are shown in Fig. S10 (ESI $\dagger$ ). The results show that the integrated photocurrents from the IPCE spectra match well with the measured $J_{\text {sc }}$. Stability studies showed that devices comprising TPB(2-TPTZ) as the HTM show greater stability for over 300 hours retaining 85\% initial efficiency (Fig. S15, ESI $\dagger$ ) under dark storage conditions in a dry box, at $25{ }^{\circ} \mathrm{C}$ temperature and a relative humidity of $30 \%$. On the other hand, TPB(2-MeOTAD) and spiro-MeOTAD based device stability tests showed that $75 \%$ and $72 \%$ of initial efficiencies were retained, respectively. This indicates that faster degradation must be associated with higher hydrophilic dimethoxydiphenylamine substituents and stability superiority of more hydrophobic phenothiazine based HTMs.

To further evaluate the commercial viability of these newly developed hole conductors we have calculated cost-per-peak-Watt

Table 2 Device characteristics of the most efficient cells

\begin{tabular}{lccccc}
\hline Name & $J_{\mathrm{sc}} / \mathrm{mA} \mathrm{cm}^{-2}$ & $V_{\mathrm{OC}} / \mathrm{V}$ & $\mathrm{FF} / \%$ & $\eta / \%$ & $R_{\mathrm{S}} / \Omega \mathrm{cm}^{-2}$ \\
\hline TPB(2-MeOTAD) & 19.32 & 0.97 & 64.54 & 12.14 & 9.10 \\
TPB(2-TPTZ) & 8.89 & 0.88 & 55.30 & 4.32 & 28.71
\end{tabular}

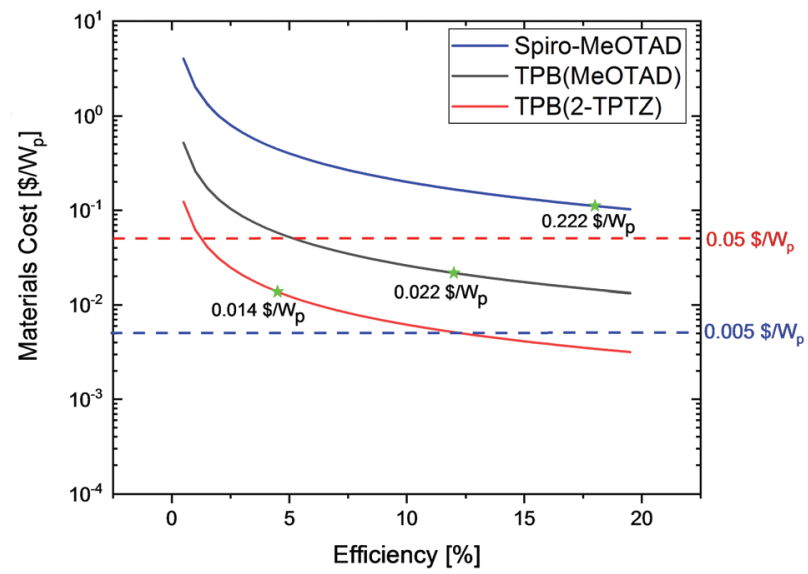

Fig. 6 Calculated material cost-per-peak-Watt $\left(\$\right.$ per $\left.W_{p}\right)$ as a function of solar cell efficiency. The star marks indicate device efficiencies delivered in this work.

as a function of solar cell efficiency, according to the method reported by Osedach et al. ${ }^{29}$ The curves shown in Fig. 6 clearly indicate that state-of-the-art HTM spiro-MeOTAD, even at very optimistic cost per gram of only $100 \$$, will contribute more than $40 \%$ to the final module cost (assuming a target module cost of $0.50 \mathrm{~S}$ per $\left.\mathrm{W}_{\mathrm{p}}\right)^{39}$ failing to fit the theme of inexpensive and scalable solar cell technology, even at efficiencies as high as $20 \%$. On the other hand, due to the very low cost of TPB(2-TPTZ) implementation of this material in the solar cell delivers the lowest material cost per peak Watt contribution with prospects of further cost reduction to as low as $0.005 \$$ per $W_{p}$ if efficiencies above $12 \%$ were achieved.

\section{Conclusions}

This study shows that by using a triphenylbenzene core, the solubility of a HTM can be largely improved, relative to a spirocarbon based material with the same substituents. Thus, more rigid and planar starting materials can be employed for HTM synthesis. In particular, we were able to use, for the first time, the phenothiazine unit to form a highly soluble hole transport material. This work demonstrates a route to employ a substituent with highly attractive properties including ultra-low cost, a desirable HOMO energy level and good rigidity for hole mobility and thermal stability.

These results underline the necessity of a deeper insight into designing materials as hole conductors for perovskite solar cells taking into account trade-offs between conversion efficiency, scalability and cost in order to deliver materials for large-scale production i.e. commercially viable. We therefore believe that our approach will be of broad interest as it is the first work to identify the use of phenothiazine to reduce the cost of functioning hole-transport materials in perovskite solar cells. We acknowledge that further efficiency improvement is desirable, but believe that this initial report will be important in catalysing further work in this direction. 


\section{Conflicts of interest}

There are no conflicts to declare.

\section{Acknowledgements}

M. R. M. and N. R. acknowledge the European Union's Horizon 2020 Research and Innovation Programme H2020-MSCA-IF2014-659237 for financial support.

\section{Notes and references}

1 W. S. Yang, B. W. Park, E. H. Jung, N. J. Jeon, Y. C. Kim, D. U. Lee, S. S. Shin, J. Seo, E. K. Kim, J. H. Noh and S. Il Seok, Science, 2017, 356, 1376-1379.

2 N.-G. Park, M. Grätzel, T. Miyasaka, K. Zhu and K. Emery, Nat. Energy, 2016, 1, 16152.

3 Q. Han, Y.-T. Hsieh, L. Meng, J.-L. Wu, P. Sun, E.-P. Yao, S.-Y. Chang, S.-H. Bae, T. Kato, V. Bermudez and Y. Yang, Science, 2018, 361, 904-908.

4 C. Kou, S. Feng, H. Li, W. Li, D. Li, Q. Meng and Z. Bo, ACS Appl. Mater. Interfaces, 2017, 9, 43855-43860.

5 Z.-Z. Z. Sun, Y.-L. L. Xu, R. Zhu and H.-Y. Y. Liu, Org. Electron., 2018, 63, 86-92.

6 M. Maciejczyk, A. Ivaturi and N. Robertson, J. Mater. Chem. A, 2016, 4, 1-22.

7 J.-Y. Seo, H.-S. Kim, S. Akin, M. Stojanovic, E. Simon, M. Fleischer, A. Hagfeldt, S. M. Zakeeruddin and M. Grätzel, Energy Environ. Sci., 2018, 11, 2985-2992.

8 M. A. Green, Y. Hishikawa, E. D. Dunlop, D. H. Levi, J. HohlEbinger and A. W. Y. Ho-Baillie, Prog. Photovoltaics Res. Appl., 2018, 26, 3-12.

9 Y.-C. Chen, S.-K. Huang, S.-S. Li, Y.-Y. Tsai, C.-P. Chen, C.-W. Chen and Y. J. Chang, ChemSusChem, 2018, 11, 3225-3233.

10 L. Wang, J. Zhang, P. Liu, B. Xu, B. Zhang, H. Chen, A. K. Inge, Y. Li, H. Wang, Y.-B. Cheng, L. Kloo and L. Sun, Chem. Commun., 2018, 54, 9571-9574.

11 Y. Li, K. R. Scheel, R. G. Clevenger, W. Shou, H. Pan, K. V. Kilway and Z. Peng, Adv. Energy Mater., 2018, 8, 1801248.

12 Š. Daškevičiūtè, N. Sakai, M. Franckevičius, M. Daškevičienė, A. Magomedov, V. Jankauskas, H. J. Snaith and V. Getautis, Adv. Sci., 2018, 5, 1700811.

13 A. Magomedov, S. Paek, P. Gratia, E. Kasparavicius, M. Daskeviciene, E. Kamarauskas, A. Gruodis, V. Jankauskas, K. Kantminiene, K. T. Cho, K. Rakstys, T. Malinauskas, V. Getautis and M. K. Nazeeruddin, Adv. Funct. Mater., 2018, 28, 1704351.

14 H. D. Pham, T. T. Do, J. Kim, C. Charbonneau, S. Manzhos, K. Feron, W. C. Tsoi, J. R. Durrant, S. M. Jain and P. Sonar, Adv. Energy Mater., 2018, 8, 1703007.

15 D. Li, J.-Y. Shao, Y. Li, Y. Li, L.-Y. Deng, Y.-W. Zhong and Q. Meng, Chem. Commun., 2018, 54, 1651-1654.
16 F. Zhang, S. Wang, H. Zhu, X. Liu, H. Liu, X. Li, Y. Xiao, S. M. Zakeeruddin and M. Grätzel, ACS Energy Lett., 2018, 3, 1145-1152.

17 X. Sun, Q. Xue, Z. Zhu, Q. Xiao, K. Jiang, H.-L. Yip, H. Yan and Z. Li, Chem. Sci., 2018, 9, 2698-2704.

18 N. J. Jeon, H. Na, E. H. Jung, T.-Y. Yang, Y. G. Lee, G. Kim, H.-W. Shin, S. Il Seok, J. Lee and J. Seo, Nat. Energy, 2018, 3, 682-689.

19 L.-H. H. Xie, F. Liu, C. Tang, X.-Y. Y. Hou, Y.-R. R. Hua, Q.-L. L. Fan and W. Huang, Org. Lett., 2006, 8, 2787-2790.

20 B. Xu, D. Bi, Y. Hua, P. Liu, M. Cheng, M. Grätzel, L. Kloo, A. Hagfeldt and L. Sun, Energy Environ. Sci., 2016, 9, 873-877.

21 K. Liu, Y. Yao, J. Wang, L. Zhu, M. Sun, B. Ren, L. Xie, Y. Luo, Q. Meng and X. Zhan, Mater. Chem. Front., 2017, 1, 100-110.

22 J. Qu, X. Jiang, Z. Yu, J. Lai, Y. Zhao, M. Hu, X. Yang and L. Sun, Sci. China: Chem., 2018, 61, 172-179.

23 K. Pydzińska, P. Florczak, G. Nowaczyk and M. Ziółek, Synth. Met., 2017, 232, 181-187.

24 Z. Z. Sun, Y. L. Xu, R. Zhu and H. Y. Liu, Org. Electron., 2018, 63, 86-92.

25 V. A. Chiykowski, Y. Cao, H. Tan, D. P. Tabor, E. H. Sargent, A. Aspuru-Guzik and C. P. Berlinguette, Angew. Chem., Int. Ed., 2018, 57, 15529-15533.

26 H. Chen, W. Fu, C. Huang, Z. Zhang, S. Li, F. Ding, M. Shi, C.-Z. Li, A. K.-Y. Jen and H. Chen, Adv. Energy Mater., 2017, 7, 1700012.

27 K. Rakstys, S. Paek, G. Grancini, P. Gao, V. Jankauskas, A. M. Asiri and M. K. Nazeeruddin, ChemSusChem, 2017, 10, 3825-3832.

28 K. Rakstys, S. Paek, M. Sohail, P. Gao, K. T. Cho, P. Gratia, Y. Lee, K. H. Dahmen and M. K. Nazeeruddin, J. Mater. Chem. A, 2016, 4, 18259-18264.

29 T. P. Osedach, T. L. Andrew and V. Bulović, Energy Environ. Sci., 2013, 6, 711.

30 J. Cao, B. Wu, R. Chen, Y. Wu, Y. Hui, B. W. Mao and N. Zheng, Adv. Mater., 2018, 30, 1705596.

31 D. Trawny, M. Quennet, N. Rades, D. Lentz, B. Paulus and H.-U. Reissig, Eur. J. Org. Chem., 2015, 4667-4674.

32 M. L. Petrus, M. T. Sirtl, A. C. Closs, T. Bein and P. Docampo, Mol. Syst. Des. Eng., 2018, 3, 734-740.

33 M. L. Petrus, T. Bein, T. J. Dingemans and P. Docampo, J. Mater. Chem. A, 2015, 3, 12159-12162.

34 X. Liang, C. Wang, M. Wu, Y. Wu, F. Zhang, Z. Han, X. Lu, K. Guo and Y.-M. Zhao, Tetrahedron, 2017, 73, 7115-7121.

35 S. S. Reddy, K. Gunasekar, J. H. Heo, S. H. Im, C. S. Kim, D. H. Kim, J. H. Moon, J. Y. Lee, M. Song and S. H. Jin, Adv. Mater., 2016, 28, 686-693.

36 C. M. Cardona, W. Li, A. E. Kaifer, D. Stockdale and G. C. Bazan, Adv. Mater., 2011, 23, 2367-2371.

37 X. Liang, K. Wang, R. Zhang, K. Li, X. Lu, K. Guo, H. Wang, Y. Miao, H. Xu and Z. Wang, Dyes Pigm., 2017, 139, 764-771.

38 X. Liang, C. Wang, M. Wu, Y. Wu, F. Zhang, Z. Han, X. Lu, K. Guo and Y. M. Zhao, Tetrahedron, 2017, 73, 7115-7121.

39 D. ARPA-E (Washington), \$1/W Photovoltaic Systems White Paper to Explore a Grand Challenge from Solar, 2010. 